\title{
O lugar do ensino de filosofia no ensino médio técnico do Instituto Federal do Paraná
}

Daniel Salésio Vandresen'

Rodrigo Pelloso Gelamo"

I- Instituto Federal do Paraná, Coronel Vivida, PR, Brasil.

Contato: daniel.vandresen@ifpr.edu.br II- Universidade Estadual Paulista, Marilia, SP, Brasil.

Contato: gelamo@gmail.com

\section{Resumo}

0 objetivo deste artigo é refletir sobre o lugar do ensino de filosofia no ensino médio técnico do Instituto Federal do Paraná (IFPR). A partir da perspectiva teórica foucaultiana, este estudo pretende contribuir para o debate sobre o ensino de filosofia promovendo duas problematizações: primeiro, como uma atitude crítica da subjetividade exigida na educação tecnológica, confrontando a construção de uma subjetividade assujeitada ao modelo do capital humano com uma subjetividade que se constitui a si mesmo; segundo, identificar o pensar filosófico como uma téchne autêntica, o que permite pensar outra experiência com a técnica, rompendo com a objetividade da técnica moderna. Resgatando os conceitos da téchne grega e da Aufklärung moderna, busca-se apresentar que um dos papéis importantes da filosofia no ensino técnico seja o de possibilitar a experiência singular do cuidado de si. Desse modo, pensamos o lugar do ensino de filosofia como um espaço de experiência: onde devemos questionar a técnica (como convida Heidegger) e cuidar de nós mesmos (como aponta Foucault).

\section{Palavras-chave}

Ensino de filosofia - Subjetividade - Tecnologias do si Cuidado de si. 


\title{
The place of philosophy teaching in the technical education of Instituto Federal do Paraná
}

Daniel Salésio Vandresen'

Rodrigo Pelloso Gelamo"

\begin{abstract}
This paper aims to discuss the place of philosophy teaching in the technical secondary school of Instituto Federal do Paraná (IFPR). From Foucault's theoretical perspective, this study aims to contribute to the discussion of philosophy teaching by promoting two problematizations: first, as a critical attitude of the subjectivity required in technology education, confronting the construction of a subjectivity subjected to the human capital model with an autonomous subjectivity that is self-constructed; second, to identify the philosophical thought as an authentic téhkne, which suggests another experience with the technique, breaking the objectivity of the modern technique. Rescuing the concepts of the Greek téhkne and modern aufklärung, it argues that one of the roles of philosophy in technical education is to allow the unique experience of self-care. Thus, we think the place of philosophy teaching as an experience space: where we must question the technique (as Heidegger calls) and take care of ourselves (as pointed out by Foucault).
\end{abstract}

\section{Keywords}

Philosophy teaching - Subjectivity - Technologies of the self-Self-care. 


\section{Introdução}

Desde o retorno da filosofia aos currículos escolares, garantido pela Lei Federal $\mathrm{n}^{0}$ 11.684/08, diversas reflexões vêm sendo desenvolvidas sobre o seu ensino, que se propõe a problematizar duas questões: o que ensinar? (questão do conteúdo) e como ensinar? (questão da metodologia). No entanto, neste trabalho pretende-se pensar o lugar onde se dá o ensino de filosofia. Com isso, não se quer dizer que a questão do conteúdo e da metodologia não sejam importantes, mas que o espaço do ensino da filosofia também é uma questão fundamental e que determina o que ensinar e como ensinar. Assim, propõe-se pensar o ensino de filosofia como o lugar de conflito entre a transmissão de saber objetivista/conteudista e a filosofia como um fazer humano que promove o cuidado de si.

o lugar em que inflexionamos nosso pensamento para pensar essa questão é, particularmente, o ensino médio técnico no Instituto Federal do Paraná (IFPR) ${ }^{1}$. Os Institutos Federais de Educação, Ciência e Tecnologia têm sua origem com a Lei $n^{\circ} 11.892$, de 29 de dezembro de 2008, a qual institui a Rede Federal de Educação Profissional, Científica e Tecnológica, vinculada ao Ministério da Educação, no âmbito do sistema federal de ensino. O Instituto Federal do Paraná (IFPR) começou suas atividades em 2009 e tem como especificidade de ensino a formação técnica de nível médio até a pós-graduação, sendo que o que chama atenção é que sua expansão inicial se dá pelo ensino de nível médio. Como a identidade do IFPR é promover a educação profissional e tecnológica, este artigo visa discutir qual seria o papel do ensino da filosofia na formação de uma subjetividade para este ambiente de formação.

Consideramos que, pelo fato de os institutos serem uma instituição recente, torna-

1- 0 objetivo é refletir sobre os pressupostos que fundamentam o ensino de filosofia no ensino médio técnico. Por isso, não se pretende descrever os aspectos históricos do desenvolvimento do ensino técnico no Brasil, mas tão somente indicar um caminho de análise que evidencie o exercício filosófico como um modo de vida. se ainda mais indispensável analisar os rumos que suas diretrizes traçarão para conquistar a formação de um sujeito emancipado. Ideal presente na concepção das diretrizes que dão base para a educação profissional e tecnológica dos institutos federais, quando afırmam: "A educação para o trabalho nessa perspectiva entende-se como potencializadora do ser humano, enquanto integralidade, no desenvolvimento de sua capacidade de gerar conhecimentos a partir de uma prática interativa com a realidade, na perspectiva de sua emancipação" (BRASIL, 2010, p. 33-34). Diante dessa proposta, busca-se compreender que tipo de emancipação subjaz este modelo de educação para o trabalho.

Assim, propomos, em um primeiro momento, analisar a contribuição do ensino de filosofia como uma atitude crítica da subjetividade exigida pelo atual modelo econômico de trabalho e como forma de análise das concepções que fundamentam a educação tecnológica nos institutos federais de educação; em seguida, identificar o pensar filosófico como uma téchne autêntica que, através da prática de si, permita pensar outra experiência com a técnica, rompendo com a objetividade da técnica moderna que está alicerçada em uma racionalidade calculista da vida. Com esses dois momentos, busca-se marcar duas interpretações da técnica, uma que joga o sujeito para fora de si e o subjuga ao modelo econômico e, outra que, ao colocar o sujeito em relação consigo mesmo, lhe permite resistir e constituir-se de uma forma ética.

\section{A questão da subjetividade: liberação ou assujeitamento?}

Vivenciamos um contexto de ampliação do avanço científico e tecnológico, expresso nas diversas conquistas tecnológicas e nos objetos produzidos, mas que também se propaga sobre a vida (a existência, a subjetividade) e difundese também pela educação tecnológica. $\mathrm{Na}$ educação, há expansão de cursos profissionais na área tecnológica, além do intenso debate 
sobre a inclusão das tecnologias na prática pedagógica. Essa incorporação do técnico sobre o agir humano também é expressa por Eladio C. P. Craia (2003, p. 16):

0 que está em pauta é a capacidade de pensar na caracterização deste momento determinado da história do homem onde o sentido do mundo, na sua quase totalidade, é expresso através do constante aparecimento do técnico. 0 próprio homem, o seu horizonte de existência, sua libido e seu pathos primordial são abarcados pelo técnico.

Frequentemente nota-se nossa época sendo caracterizada como a era da técnica ou era tecnológica, pois o progresso tecnológico tem possibilitado ao homem diversas conquistas, por exemplo, no campo da comunicação, com diferentes mecanismos que possibilitam a veiculação do pensamento, e na área da saúde, com medicamentos e aparelhos que garantem o prolongamento da vida. Diante de todas as potencialidades proporcionadas e prometidas pelo desenvolvimento tecnológico, questiona-se: estaríamos em um momento privilegiado em que o uso das tecnologias poderiam proporcionar maior espaço para a expressão da subjetividade, da liberdade e do bem-estar social?

Diante deste cenário e da atual proposta de política pública educacional para o ensino técnico, a leitura que segue propõe pensar o ensino de filosofia no ensino médio técnico a partir de duas problematizações: uma diz respeito à subjetividade exigida na formação técnica; e a outra refere-se ao sentido do ensino da filosofia como problematização de nossa experiência com a técnica.

Na primeira problematização, procura-se tematizar o direcionamento de uma formação técnica para adequar-se ao modelo econômico, na qual se produz uma subjetividade assujeitada por meio dos modelos da objetividade e das competências. Nesse sentido, o conceito de capital humano (FOUCAULT, 2008, p. 315), desenvolvido por Foucault na obra Nascimento da biopolitica (cursos de 1978/79), torna-se uma ferramenta importante para analisar e desvelar os interesses econômicos que agem sobre a educação para formar um determinado tipo de subjetividade. Assim, expressa:

[...] um capital humano no curso da vida dos indivíduos, que se colocam todos os problemas e que novos tipos de análise são apresentados pelos neoliberais. Formar capital humano, formar portanto essas espécies de competência-máquina que vão produzir renda, ou melhor, que vão ser remuneradas por renda, quer dizer o quê? Quer dizer, é claro, fazer o que se chama de investimentos educacionais. (FOUCAULT, 2008, p. 315).

Entende-se por capital humano uma ação econômica que age sobre a vida do homem, portanto, biopolítica, produzindo um trabalhador empresário de si mesmo (FOUCAULT, 2008, p. 311), que por meio de investimentos em sua educação adquire competências para gerar renda. Quanto mais valor agregado ao seu capital humano, maior a possibilidade de aumento de renda, mas também maior a possibilidade de desenvolvimento econômico, crescimento de uma empresa e como forma de governo neoliberal. 0 tema principal do curso de 1978/79 é apresentar a arte de governo neoliberal, onde Foucault descreve (2008, p. 298), a partir das concepções da Escola de Chicago nos Estados Unidos do século XX, o desenvolvimento de uma racionalidade estratégica de governo da vida que passa a conceber o comportamento humano como um elemento econômico.

Para Foucault (2008, p. 315), os investimentos educacionais que produzem o capital humano na economia neoliberal vão além da prática do aprendizado escolar e profissional. Ele passa pelo tempo em que os pais dedicam-se à formação dos filhos, que não depende apenas do nível cultural dos pais, mas também de suas condições econômicas; famílias mais abastadas 
oferecem mais qualidade no cuidado e vigilância dos seus filhos. Passa também pelos problemas de higiene pública e proteção à saúde. 0 cuidado médico com a saúde do indivíduo constitui um investimento no capital humano, conservando e utilizando-o pelo maior tempo possível. Sendo que essa busca por construir um capital humano invade a vida do indivíduo desde a mais tenra idade até a velhice.

Para os neoliberais, o capital humano é constituído de elementos inatos e adquiridos, mas são os elementos que o indivíduo adquire ao longo da vida a preocupação das análises neoliberais (FOUCAULT, 2008, p. 312). Para isso, os investimentos educacionais tornam-se uma ferramenta indispensável nessa lógica econômica. Investimento realizado não apenas pelo indivíduo, mas por empresas e pelo Estado, com vistas a melhorar as competências desse capital humano. Portanto, a formação educacional aparece no governo neoliberal como elemento estratégico para seu funcionamento, pois induz os próprios indivíduos a assumirem essa tarefa.

Foucault (2008, p. 370) questiona se todos esses investimentos poderiam produzir um sujeito capaz de átomos de liberdade; sua resposta é negativa, pois o que acontece é a formação de um tipo de sujeito que se regula de acordo com o que rege a economia. A educação, além de constituir na sociedade de controle uma ferramenta capaz de instigar o indivíduo a estar sempre investindo em seu capital humano, também funciona como um poderoso elemento de sujeição, ou seja, um instrumento político para direcionar as condutas individuais $\mathrm{e}$ coletivas sob o modelo das competências e da criatividade.

É o que acontece, por exemplo, com a ideia de formação permanente/continuada. Gilles Deleuze (1992), no texto Post-Scriptum sobre as sociedades de controle, relaciona a formação permanente com o que chama de sociedade de controle. Para o autor, a educação em uma sociedade de controle aparece sob o modelo da empresa, ou seja, nessa realidade cria-se um ambiente de competição, tendo como princípio o salário por mérito e a ênfase na formação permanente. 0 autor aponta que na sociedade disciplinar é preciso sempre recomeçar, seja na escola, na fábrica etc.; enquanto que na sociedade de controle nunca se termina nada. Nessa sociedade de controle, Deleuze descreve o que marca o regime das escolas: “[...] as formas de controle contínuo, avaliação contínua, e a ação da formação permanente sobre a escola, o abandono correspondente de qualquer pesquisa na Universidade, a introdução da 'empresa' em todos os níveis de escolaridade" (DELEUZE, 1992, p. 225).

Agora, pretende-se descrever como esta leitura se relaciona com os conceitos de técnica e tecnologia no próprio Foucault, elementos importantes para questionarmos essa subjetividade objetivada e pensarmos o lugar da filosofia no ensino técnico. Em 1982, no texto As tecnologias do eu, Foucault apresenta quatro tipos de técnicas/tecnologias que são base para a formação das racionalidades práticas:

[...] estas técnicas podem ser divididas em quatro grupos, cada uma das quais é uma matriz da razão prática: 1) as técnicas de produção pela qual podemos produzir, transformar e manipular objetos; 2) os sistemas técnicos de signos, que permitem o uso de signos, os significados, os símbolos ou as significações; 3) as técnicas de poder, que determinam a conduta dos indivíduos, para submetê-los a determinados fins ou dominação, objetivando enquanto sujeito; 4) as técnicas do eu, que permitem aos indivíduos realizar, sozinho ou com a ajuda de outros, um certo número de operações sobre seus corpos e almas, pensamentos, conduta, seu modo de ser; para transformar a fim de atingir um estado de felicidade, pureza, sabedoria, perfeição ou imortalidade. (FOUCAULT, 1994, p. 785, tradução nossa).

Para o autor, embora tais técnicas não atuem de modo independente umas em relação 
às outras, cada uma delas atua modificando a conduta do indivíduo por meio de práticas educacionais que visam adquirir um conjunto de habilidades e também de comportamentos. Sendo que, "cada um desses tipos implica em certos modos de educação e de transformação dos indivíduos, na medida em que se trata não somente, evidentemente, de adquirir certas aptidões, mas também adquirir certas atitudes" (FOUCAULT, 1994, p. 785, tradução nossa). Para Foucault, os conceitos de técnica e tecnologia, entendidos como tática e estratégia, visam compreender que a mesma lógica objetivante da técnica, presente nas técnicas de produção, também estão atuantes nas técnicas de dominação (poder disciplinar e biopoder) e, enfım, determinam os propósitos pelos quais os sujeitos são objetivados. Nisso deve ser entendida sua descrição do conceito de capital humano, que funciona como uma tecnologia de dominação, visando a formação de um sujeito flexível e criativo, capaz de múltiplas habilidades, procedimentos que o permitem alcançar fins desejados já determinados. Um saber técnico que procura atender a uma racionalidade calculista que impera na economia, ou seja, uma lógica baseada em investimento e resultado.

Para Foucault, esses poderes que direcionam a subjetividade na modernidade devem ser pensados a partir das tecnologias de dominação, como o poder disciplinar e o biopoder, e, também, questionados a partir das tecnologias do eu, da liberdade e da resistência, em busca de novos estilos de existência. Esse empreendimento teórico, elaborado pelo filósofo francês, constitui-se em uma ferramenta importante para analisar as formas de libertação de um modelo de pensar que se conduz predominantemente pela racionalidade instrumental, como já apontou a Escola de Frankfurt. Daí a importância dessa reflexão para o ensino técnico, o qual predominantemente se conduz por uma racionalidade governada por princípios técnicos e científicos.

Esse diagnóstico do presente permite que o autor conceba a técnica moderna, em sua determinação instrumental, como produção de uma subjetividade assujeitada. Seus estudos genealógicos sobre as tecnologias de dominação (de poder e de biopoder) permitem compreender que os conceitos de técnica e tecnologia entendidos pelo autor como tática e estratégia - funcionam na mesma lógica objetivante da técnica que está presente nas técnicas de produção. E, assim, determinam os propósitos pelos quais os sujeitos são objetivados. Compreende-se por lógica objetivante um modo de conduzir os indivíduos que tem como resultado fins já determinados. Sendo que cada tipo de tecnologia implica certos modos de educação e transformação dos indivíduos (FOUCAULT, 1994, p. 785). Desse modo, as tecnologias de dominação biopolíticas agem como técnicas de apropriação do indivíduo, limitando seu modo de ser e de pensar.

Nossa maneira de pensar é determinada pelo modo objetivista do fazer técnico, o qual funciona na lógica da eficiência, ou seja, prioriza um jogo calculista de procedimentos ou meios para conquistar fins determinados. Sendo a modernidade o momento em que foram intensificados e aperfeiçoados os mecanismos para alcançar com maior rapidez o fim desejado. Estando essa mesma lógica funcionando na educação, pois o determinismo tecnológico, expresso na objetividade dos métodos, avaliações mensuráveis e na formação de espíritos flexíveis, vemos impossibilitado o desenvolvimento do pensamento crítico enquanto capacidade de diagnóstico e resistência.

A educação moderna, limitada ao uso de técnicas para formação de competências do sujeito econômico, converteu-se em tecnologia de poder/dominação (FOUCAULT, 1994, p. 795). Isso pode ser percebido nos processos de ensino que, alicerçados em princípios da objetividade técnica, universalizam um mesmo procedimento (método) para todos chegarem a um mesmo fim, o que tem como consequência não possibilitar um espaço formativo existencial, ético e político. Desse modo, a educação 
moderna transforma-se em tecno-saber, ou seja, um saber que é profundamente marcado pela objetividade técnica. A educação passa a funcionar como um "poder biotécnico" (RABINOW; DREYFUS, 1995, p. XXII), um poder que controla a vida por procedimentos técnicos. Dito de outra maneira, a educação transforma-se em um saber biotécnico, pois a objetividade de seu saber técnico tem por fınalidade gerir a vida pela lógica da formação do capital humano.

A segunda problematização diz respeito ao questionamento do lugar do ensino de filosofia no ensino técnico. 0 ensino de filosofia precisa ir além do tradicional ensino de abordagem estrutural da história da filosofia (conteudista) e propor tematizar filosoficamente nossa experiência presente com a técnica. Com isso, não se quer afirmar que a única forma de se fazer filosofia seja através do questionamento da técnica, mas, sim, defender que o lugar onde se dá o ensino de filosofia requer um pensar crítico sobre o nosso modo de ser marcado pelo fazer técnico.

Segundo Foucault (2010, p. 317-318), prevalece com frequência dois esquemas no estudo da história da filosofia, um que pretende resgatar uma origem radical em que a verdade consistiria em descobrir algo como um esquecimento e, outro, a história da filosofia como o desenvolvimento de uma racionalidade. Duas posturas que se pretende evitar, propondo pensar a filosofia como um jogo diverso do dizer a verdade que leva à constituição do sujeito por si mesmo.

Postura que nos leva a pensar o ensino da filosofia não mais como preparação para uma objetividade, seja da verdade ou da racionalidade, mas como uma experiência em que o que está em jogo é a própria constituição de si. Em outro texto, Rodrigo P. Gelamo, ao tratar da filosofia como experiência ligada à vida e não à objetividade, afırma: “[...] 0 ensino da filosofia precisaria se dar como uma experiência de pensar e não como um vínculo às regras e às objetividades capazes de produzir um pensamento verdadeiro" (GELAMO, 2010, p. 397). Sendo que a experiência fundamental a ser problematizada no ensino de filosofia, principalmente em um ensino técnico, refere-se à nossa relação com a técnica.

Atitude inicialmente proposta por Heidegger, no texto de 1953, A questão da técnica. "Questionemos a técnica", convida Heidegger (2007, p. 375). 0 autor alemão revela a filosofia como uma atitude que permite interrogar o presente, para mostrar o modo como nosso ser se constitui nessa experiência com a técnica. Foucault mesmo admite (2012, p. 253) que a leitura de Heidegger na década de 1950, como a de Nietzsche, foi decisiva em seus trabalhos futuros. 0 autor francês afirma:

Para Heidegger, é a partir da téchne ocidental que o conhecimento do objeto selou o esquecimento do Ser. Retornemos à questão e perguntemo-nos a partir de quais téchnai se formou o sujeito ocidental e foram abertos os jogos de verdade e erro, de liberdade e coerção que os caracterizam. (FOUCAULT apud GROS, 2004, p. 634-635, grifo nosso).

Para Heidegger (2007), a essência da técnica não é nada técnico, isto porque a técnica não pode determinar nem ser o fundamento de si mesma. A palavra questionar revela sua compreensão da filosofia como uma atitude que permite interrogar o presente, para mostrar o modo como nosso ser se constitui nesse momento. Afirma ainda que esse questionar deve ser construído em um movimento que chama o caminho do pensamento. 0 questionamento do que a técnica é revela sua descrição do modo de proceder da técnica moderna. Segundo Heidegger (2007, p. 376), há dois enunciados que manifestam essa questão: o primeiro, "técnica é um meio para fıns" (determinação instrumental) e, o segundo, "técnica é um fazer do homem” (determinação antropológica) ${ }^{2}$. Com isso, não pretende destruir a técnica, pois não há

2- Em outro texto, A época da imagem do Mundo (1938), Heidegger também desenvolve a constituição da objetividade da ciência moderna atrelada à formação do sujeito moderno. 
como escapar a essa atividade que caracteriza o humano; a técnica manifesta o próprio vir a ser do homem. Antes, quer superar as visões antropológicas e instrumentais da técnica, que, baseadas na causalidade, constroem uma visão neutra da técnica. Concepção de neutralidade que determina nosso domínio sobre técnica e que conduz a certos riscos. "Quanto mais se quer dominar a técnica, tanto mais ela escapa ao controle e reaviva a vontade humana de controlá-la numa espiral de conseqüências imprevisíveis" (DUARTE, 2009). Evitar esses riscos, questionando a técnica, permite construir uma relação livre com ela, superando a determinação da técnica moderna, que limita o agir humano a um fazer instrumental.

Heidegger questiona a técnica ocidental mostrando que seu conhecimento objetivo determinou o esquecimento do ser e não permite seu desvelamento. Sua leitura permite questionar a técnica moderna, a qual, alicerçada em um saber objetivo, impede a manifestação de outras formas de pensamento.

Já a leitura de Foucault mostrará que o sujeito ocidental se constitui a partir de certas técnicas de dominação, as quais determinam como vai ser sua relação com a verdade e a liberdade. No texto Verdade e subjectividade (conferência de 1980, publicado em 1993), Foucault expressa o que entende por tecnologia:

[...] domínio exacto da análise é aquilo a que eu daria o nome de tecnologias. Significando isto a articulação de certas técnicas e de certos tipos de discurso acerca do sujeito. (FOUCAULT, 1993, p. 206).

Com a aplicação desses conceitos de técnica e tecnologia, Foucault pretende analisar certa dimensão da realidade que compõe as práticas racionalizadas, que agem sobre os indivíduos por meio de uma regularidade de táticas e estratégias, sendo que nisso se manifesta o modo como o poder é exercido. Essa é a interpretação que Edgardo Castro (2009) realiza nos verbetes técnica e tecnologia na obra
El vocabulario de Michel Foucault, as práticas são o campo de estudo de Foucault e elas se definem pela regularidade e a racionalidade que acompanham seu modo de ser. Sendo que os termos técnica e tecnologia agregam a ideia de prática nos conceitos de estratégia e tática.

Foucault admite (2004, p. 589) que busca compreender como se formou a objetividade no pensamento ocidental, como em determinado momento o mundo tornou-se o correlato de uma téchne. Ainda afirma: "Quero com isto dizer que, a partir de um certo momento, ele [mundo] cessou de ser pensado para tornar-se conhecido, medido, dominado, graças a alguns instrumentos e objetivos que caracterizavam a téchne, ou as diferentes técnicas" (FOUCAULT, 2004, p. 589-590, nossa inclusão). Para Gros (2004, p. 595), o uso dos conceitos de técnica e tecnologia nos trabalhos de Foucault pode ser atribuído à influência recebida de Heidegger. A leitura de Foucault, assim como a de Heidegger, evidencia que a técnica moderna é o modo como o ser humano se relaciona com o mundo e consigo mesmo.

Dessa maneira, pode-se evidenciar que a aplicação que Foucault faz dos conceitos de técnica e tecnologia visa compreender que a mesma lógica objetivante da técnica, presente nas técnicas de produção, também estão atuantes nas técnicas de dominação e, enfım, determinam os propósitos pelos quais os sujeitos são objetivados. Isto é, o autor procurou mostrar em seus estudos, acerca da técnica disciplinar, a racionalidade e sua necessidade de confinar o louco (História da loucura) e vigiar o delinquente (Vigiar e punir), assim como nos estudos da técnica biopolítica, o governo da vida pela teoria do capital humano (Nascimento da biopolítica). Do mesmo modo que a técnica da produção produz uma objetividade sobre seu objeto, o saber-poder funciona como uma técnica objetivante do sujeito.

Nessa perspectiva, torna-se fundamental que o ensino de filosofia problematize nossa experiência com a técnica. Pensar o lugar do ensino da filosofia enquanto pensamento 
crítico sobre a atualidade da técnica implica em proporcionar um processo educacional que seja conduzido pela formação humana de si mesmo. Para isso, pretende-se apresentar no próximo tópico, a partir da perspectiva foucaultiana, a filosofia como um instrumento fundamental para o cuidado de si, questão que para o autor está ligada aos conceitos da téchne grega e a Aufklärung moderna ${ }^{3}$.

\section{O ensino da filosofia como téchne autêntica}

Este tópico tem por objetivo descrever, a partir da perspectiva foucaultiana, a filosofia como um instrumento fundamental para o cuidado de si. Dessa forma, o ensino de filosofia passa a ter um papel indispensável na educação técnica, pois deve proporcionar ao educando outra experiência com a técnica, superando a determinação instrumental moderna.

Uma primeira ideia que aparece nos escritos de Foucault diz respeito à ligação da filosofia com o conceito da téchne grega: enquanto dizer verdadeiro (parresía) e cuidado de si (epiméleia heautô̂). Assim, afirma o filósofo: “[...] a tékhne filosófica do logos é uma tékhne que possibilita ao mesmo tempo o conhecimento da verdade e a prática ou a ascese da alma sobre si mesma" (FOUCAULT, 2010, p. 304). E ainda: “[...] o filósofo será verdadeiramente o parresiasta [...]. A filosofia, por sua vez, é étymos téchne (a técnica autêntica) do discurso verdadeiro" (FOUCAULT, 2010, p. 305). 0 que leva a concluir que, para o autor, a técnica autêntica do discurso (logos) verdadeiro se realiza pela filosofia. Desse modo, concebe a filosofia como uma técnica que, por meio da experiência do discurso verdadeiro (parresía), possibilita a condução de si mesmo em uma experiência singular de si.

Segundo Foucault (2004, p. 450), a parresía significa a liberdade do dizer

3 - Foucault, retomando o pensamento de Kant, concebe a filosofia como uma atitude iluminista de problematização do presente manifestado pelo esclarecimento (Aufklärung). Tema desenvolvido no próximo tópico. verdadeiro, por isso, está ligada a um êthos "a maneira de ser e a maneira de se conduzir" (FOUCAULT, 2012, p. 264) - e uma téchne (procedimento técnico), ambas indispensáveis para a constituição de si. A atitude da parresía, enquanto busca pelo equilíbrio entre o que se fala e o que se vive, torna-se um elemento indispensável para o cuidado de si.

Ao traçar a história da parresía, Foucault, na obra $A$ coragem da verdade (curso de 19831984), defende (2011, p. 111, p. 140 e p. 216) que houve duas práticas filosóficas no Ocidente oriundas da filosofia platônica, representadas pelos diálogos de Alcibiades e Laques. "Uma vai à metafísica da alma (o Alcibiades), a outra a uma estilística da existência (o Laques)" (FOUCAULT, 2011, p. 140). Em Alcibiades, o conhecimento de si se desenvolve como um modo de descoberta da alma (a psykhé), como realidade ontológica distinta do corpo. Já em Laques, a questão de si aparece como um modo de condução da vida (bios), como uma maneira de ser e fazer. Contudo, apesar das diferenças, há algo em comum nesses textos, a parresía socrática como um modo de reconhecer que é preciso cuidar de si mesmo (FOUCAULT, 2011, p. 138-139).

Segundo Foucault (2004, p. 66), Platão no texto Alcibiades Primeiro afirma que, para ocuparmo-nos de nós mesmos, é preciso saber o que significa este nós mesmos. "Na fórmula epimeleîsthai heautoû, o que é o heautoû? É preciso gnônai heautô, diz o texto" (FOUCAULT, 2004, p. 66). Desse modo, o cuidado de si exige duas posturas: uma, conhecer a si mesmo (gnônai heautoû), e, a outra, praticar a ascese, ou seja, um conjunto de exercícios físicos e intelectuais que tem por finalidade a constituição do sujeito por meio da relação consigo mesmo (FOUCAULT, 2012, p. 259).

Para Foucault, na filosofia grega há uma ligação indispensável entre o cuidado de si e a verdade/conhecimento de si. Ligação que, segundo Foucault (1994), é rompida na Idade Moderna com a filosofia de René Descartes. Nesse momento, se produziu um esquecimento do cuidado de si em função do predomínio do 
conhecimento de si, o qual se tornou princípio fundamental para a constituição do cogito. Para situar a cisão, o autor desenvolve (no curso A hermenêutica do sujeito de 1981/82) um estudo sobre a história do cuidado de si ou técnicas de si, no qual aponta seu início com o modelo platônico do princípio socrático do conhece-te a ti mesmo e tendo seu apogeu no período helenístico, em que o cuidado de si visava a autonomia do indivíduo através de práticas que tinham como principal objetivo a transformação de si em busca de um estilo de existência. Já durante a pastoral cristã, as técnicas que compõem o cuidado de si (epimeleia heautou) foram gradativamente sendo deslocadas para um cuidado pelos outros (epimeleia ton allon). Na pastoral cristã, houve um governo de si através de um conjunto de práticas que visavam a sujeição do indivíduo a padrões de conduta externos (as técnicas de confissão, exame da consciência e dramatização das penitências constituíram verdadeiros processos de sujeição e de renúncia de si). Com a modernidade, a primazia do conhecimento de si produziu um saber objetivo e calculista da vida. 0 que o leva a apontar o desenvolvimento de uma racionalidade política de Estado, que se utiliza de técnicas objetivistas para controlar a vida administrativamente (como o controle da natalidade e da mobilidade, por exemplo). Aponta ainda que atualmente se desenvolve uma forma de governo como controle da vida, que chama de biopolítica, ideia já descrita acima na análise do curso Nascimento da biopolítica de $1978 / 79^{4}$.

Já a partir do texto de Laques, Foucault (2011) procura mostrar como no pensamento grego a existência (bios) se constitui como objeto estético; em suas palavras: “[...] o bios como uma obra bela” (FOUCAULT, 2011, p. 141). E como esta linha da filosofia foi encoberta e dominada pela história da metafísica da alma. É a partir deste princípio da parresía socrática

4- Optou-se por relatar rapidamente este percurso, pois descrever os diferentes momentos deste percurso histórico não faz parte do objetivo deste trabalho. que Foucault (FOUCAULT, 2011, p. 127 e 130) apresenta que o cuidado de si supõe um dizer verdadeiro como prova de vida. "É preciso submeter a vida a uma prova de toque para separar exatamente o que é bom do que não é bom no que se faz, no que se é, na maneira de viver" (FOUCAULT, 2011, p. 127). Exame do modo de vida que deve ser perseguido durante toda a vida, pois não há modelo a ser seguido; não há competência técnica que uma vez adquirida possa ser reativada. Enfim, trata-se de fazer uma "história da vida como beleza possível” (FOUCAULT, 2011, p. 141).

Nesse mesmo sentido, na obra Hermenêutica do sujeito, Foucault (2004, p. 543) identifica o cuidado de si (epiméleia heautoû) com a necessidade na cultura grega de uma téchne da existência. A téchne grega é também uma arte, uma arte da existência, que Foucault chama de téchne tồ biou (técnica da vida), onde fazer da vida uma técnica implica necessariamente a liberdade e a escolha daquele que utiliza sua téchne. Essa arte da existência (FOUCAULT, 2004, p. 513s) não deve obedecer a uma vida regrada, pois esta não permite $o$ aperfeiçoamento da vida; não regra, mas uma forma de vida, ou seja, buscar constituir um estilo de vida, uma forma de vida que se constitua em uma obra bela.

Para os gregos o importante é saber como viver, sendo que "o problema se constituía em qual técnica devo utilizar para viver da melhor maneira possível" (FOUCAULT, 1995, p. 259). Também em outra passagem, o filósofo expressa essa preocupação dos gregos: “[...] qual é o saber que me possibilitará viver como devo viver, como devo viver enquanto indivíduo, enquanto cidadão, etc.?" (FOUCAULT, 2004, p. 219). Resposta que deveria se configurar como busca por um estilo de vida, no qual a vida pudesse se configurar em uma obra de arte portadora de valores estéticos. Estar preparado para algo que possa acontecer, eis o objetivo das técnicas (procedimentos, saberes, meditação) como forma de cuidar de si. Para preparar-se é preciso fazer da vida uma prova, 
uma preparação constante, um cuidado de si que visa prevenir-se de um acontecimento imprevisto (FOUCAULT, 2004, p. 588).

Na leitura de Foucault, a téhkne grega vai além de apenas uma atividade técnica interessada em resolver problemas práticos imediatos, como a construção de instrumentos ou a cura de uma doença, mas deve ser relacionada à busca por fazer de seus atos uma obra de arte. Assim, para os gregos a vida também é objeto de uma téhhne, pois, por meio de exercícios práticos, a vida passa a ser governada por uma racionalidade prática em que cada ato de comportamento deve servir como modelo a ser seguido.

Pensar o ensino de filosofia através do resgate do conceito da téchne grega ligado ao cuidado de si é fundamental para a superação da visão determinista da técnica. Segundo Alexandre S. Freitas (2013, p. 326s), a filosofia permite que na educação se tematize a formação de si mesmo, pois tradicionalmente a educação tem incorporado os termos sujeito e subjetividade, porém a noção de si mesmo permanece ausente das reflexões pedagógicas. Por isso, cabe ao ensino de filosofia propiciar um espaço de problematização de si, onde se possa fazer da experiência de si uma forma de cuidar de si.

Nesse mesmo sentido, Pedro A. Pagni (2011) afirma que o resgate do cuidado de si deve levar a conceber a filosofia como uma atitude ética, política e estética.

[...] o cuidado de si não apenas reverte à forma preponderante de interpretação sobre a Filosofia Antiga, como também coloca em xeque a própria função da filosofia como um ato de pensar destituído de uma atitude ética e política, ao recuperá-la como exercício de espiritualidade, como modo de vida e como arte de viver. (PAGNI, 2011, p. 31).

Para Pagni (2011), o resgate do conceito cuidado de si, realizado pela leitura foucaultiana, permite retomar a filosofia sob outro olhar. Não mais apenas pelo viés do conhecimento que através da tradição do conhece-te a ti mesmo desloca o indivíduo de seu presente, mas por meio de um exercício de si que, ao permitir o cuidar de si, torna possível um modo de vida que se conduz por um agir livre.

Nesse mesmo horizonte, Sílvio Gallo e Renata L. Aspis (2010), ao conceber o ensino de filosofia como resistência e diferença, afırmam a ligação do pensamento filosófico como um poder da vida e da criação de si. Em suas palavras:

Talvez possamos praticar um ensino que, no mínimo, e talvez isso já seja o suficiente, se o conseguirmos, faça-os saber que é possível criar, ainda. Que os faça sentir que cada um deles pode ser uma máquina de criação de versões, que a submissão não é a única saída. Isso significa que podemos tentar reativar nos jovens a ideia - e a prática - de que há um poder, o poder da vida, que é de cada um, com o qual se pode criar o mundo. (GALLO; ASPIS, 2010, p. 103).

Refletindo sobre o ensino de filosofia, Gallo e Aspis (2010, p. 104) defendem o pensamento filosófico como uma alternativa para criação de saídas; um vetor de criação de diferenças que permitem romper com as versões instituídas. Trata-se de fazer com que a potência criadora promova a vida em sua singularidade.

Com esse percurso realizado por Foucault, buscou-se compreender a constituição da subjetividade ocidental por meio da formação do cuidado de si ligado às técnicas. "A história do 'cuidado' e das 'técnicas' de si seria, portanto, uma maneira de fazer a história da subjetividade" (FOUCAULT, 1997, p. 111). E com a leitura desses autores contemporâneos, tratase de pensar a transformação de si como uma nova possibilidade estratégica, que também se utiliza de procedimentos técnicos, embora não objetivante, mas que conduz a uma estética da existência, um agir ético e uma ação política.

Outra referência à tarefa da filosofia nos escritos de Foucault diz respeito à questão kantiana sobre a atualidade (questão da 
Aufklärung ${ }^{5}$ ). Nesse sentido, o empreendimento foucaultiano pode ser visto como uma atitude pós-kantiana, isto porque, no início da década de 1980, o autor francês buscará em Kant um fundamento para a filosofia como uma história crítica do pensamento em sua atualidade. Para Foucault, quando Kant em 1784 publica um texto como resposta à questão: "Was ist Aufklärung?” (FOUCAULT, 2005a, p. 335), surge o primeiro passo para fazer da filosofia uma constante problematização do presente, postura esta que faz parte do mais íntimo que procurou praticar em sua filosofia. "'O que acontece atualmente e o que somos nós, nós que talvez não sejamos nada mais e nada além daquilo que acontece atualmente?' A questão da filosofia é a questão deste presente que é o que somos". (FOUCAULT, 2005b, p. 239).

Para Foucault, a Aufklärung permite tanto diagnosticar o modo como nos constituímos, como também, promover uma atitude (ethos).

Gostaria, por um lado, de enfatizar o enraizamento na Aufklärung de um tipo de interrogação filosófica que problematiza simultaneamente a relação com o presente, o modo de ser histórico e a constituição de si próprio como sujeito autônomo; gostaria de enfatizar, por outro lado, que o fio que pode nos atar dessa maneira à Aufklärung não é a fidelidade aos elementos de doutrina, mas, antes, a reativação permanente de uma atitude; ou seja, um êthos filosófico que seria possível caracterizar como crítica permanente de nosso ser histórico. (FOUCAUT, 2005a, p. 344-45, grifo nosso).

A questão do presente deve ser também a questão de si mesmo. A busca pela liberdade do pensamento passa pelo cuidado de si e a crítica constante sobre nós mesmos. Também defende

5- Foucault desenvolve o tema da Aufklärung nos seguintes textos: "0 que é a crítica?" [Crítica e Aufklärung]; "0 que são as luzes?" [What is enligthenment?] (2005a); "0 que são as luzes?" [Qu'est-que les lumières?] (2011) e na aula de 5 de janeiro de 1983 na obra 0 governo de si e dos outros: curso no Collège de France [1982-1983] (2010). a ideia de que a problematização do presente deve se constituir em um "[...] princípio de uma crítica e de uma criação permanente de nós mesmos em nossa autonomia" (FOUCAULT, 2005a, p. 346). Para Foucault (2012, p. 294) a Aufklärung (enquanto atitude crítica) está ligada ao quadro geral das técnicas de si (transformação de si). Atitude que chama de "ontologia do presente" ou "ontologia de nós mesmos" (FOUCAULT, 2010, p. 21).

Foucault associa (1993, p. 207) a atitude crítica à problematização das técnicas que deram forma ao conceito de sujeito ocidental. Essa crítica em sua dimensão política é "[...] uma análise relativa àquilo que estamos dispostos a aceitar no nosso mundo, a recusar e a mudar, tanto em nós próprios como nas nossas circunstâncias" (FOUCAULT, 1993, p. 207). Assim, a filosofia como atitude crítica trata das possibilidades de transformação do sujeito e de nós mesmos. Segundo Frédéric Gros (2010, p. 345s), Foucault, influenciado pela herança crítica kantiana, retoma o conceito grego do cuidado de si (técnicas de si) como uma questão ontológica e o problema real da filosofia moderna.

Ainda, em outra passagem, Gros (2004, p. 591) também trata da relação entre a Aufklärung e as técnicas de si. E cita em nota de rodapé da obra $A$ hermenêutica do sujeito uma frase que Foucault deixa de pronunciar, mas que está registrada em seu manuscrito. A frase diz: "E se a tarefa deixada pela Aufklärung [...] consiste em interrogar sobre aquilo em que se assenta nosso sistema de saber objetivo, ela consiste também em interrogar aquilo em que se assenta a modalidade da experiência de si" (FOUCAULT apud GROS, 2004, p. 591, em nota de rodapé e grifos nossos). A frase faz parte das discussões de Foucault sobre o desafio da filosofia ocidental em compreender este momento no qual o mundo tornou-se o correlato de uma téchne e, no mesmo tempo e lugar, em que se manifesta um sujeito do conhecimento. Embora deva ser também o momento em que a filosofia se realiza como uma verdade do sujeito que somos (ontologia do presente). Desse modo, a 
Aufklärung, enquanto atitude crítica, permite que o ensino de filosofia se realize como o lugar de duas atitudes: por um lado, problematizar o saber objetivo, que se manifesta principalmente no saber científico e tecnológico e, por outro, questionar o modo como fazemos a experiência de nós mesmos.

Essa interpretação da filosofia deve produzir duas atitudes críticas em seu ensino: a primeira, como atitude de resistência, rompendo com os modos e as técnicas de sujeição. É preciso pensar a educação como resistência, que, ao questionar as técnicas de dominação, promova o exercício da diferença, a transformação do presente e dos territórios estabelecidos. Nessa atitude, o ensino da filosofia se realiza como o lugar de conflito de duas interpretações da técnica: uma objetivista/conteudista e, a outra, como fazer humano que promove o cuidado de si (técnica autêntica). Segundo Gelamo (2009, p. 115), a filosofia torna-se um "saber técnico" quando transmite um tipo de conhecimento em que o objetivo é (re)conhecer a forma e o conteúdo de determinado pensamento. $\mathrm{E}$ isso tem levado ao empobrecimento da experiência da vida no ensino da filosofia (GELAMO, 2009, p. 127).

E a outra atitude, como transformação de si, em que o saber filosófico impulsione novas formas de vida. Para isso, não podemos conceber um sujeito acabado, mas que se constrói a si mesmo, sendo o ensino de filosofia um destes espaços onde a vida possa se realizar como uma obra de arte. Foucault convida à prática desta atitude ao descrever (2012, p. 280): a "função crítica da filosofia decorre [...]: 'Ocupa-te de ti mesmo', ou seja: 'Constitua-te livremente, pelo domínio de ti mesmo'”. A atitude filosófica instigada pelo princípio socrático, que vai além de um princípio de conhecimento, deve conduzir a uma transformação de si que promova formas de vidas livres.

\section{Considerações finais}

Neste trabalho, procurou-se descrever como a educação tecnológica se desenvolve como um tipo de saber biotécnico, que, alicerçado nos ideais da racionalidade instrumental, produzem como consequência o empobrecimento das capacidades de um pensamento crítico. 0 papel da educação tecnológica deve ser o de restituir uma visão da tecnologia como um modo de ser que permita denunciar seu aprisionamento instrumental e promova sua resistência por meio de novas formas de vida. É preciso pensar a educação técnica para além do modelo objetivante e da formação de competências, isso exige uma atitude de resistência enquanto atitude iluminista da crítica do presente.

Nesse sentido, torna-se importante a problematização, a partir da perspectiva foucaultiana, da articulação das tecnologias de produção e das tecnologias de poder, as quais transformam os indivíduos em produtores de produtos, um equipamento do capital. Essa temática deve ser presença imprescindível no currículo do ensino técnico, pois a formação do pensamento crítico depende do constante questionamento sobre o conceito de tecnologias. 0 profissional formado em cursos de ensino tecnológico precisa ter consciência de que uma opção tecnológica não pode ser reduzida a sua dimensão estritamente técnica. E que a implantação de sistemas tecnológicos (tecnologias de produção), bem como a opção por certos eixos tecnológicos como objeto de formação escolar, devem ser relacionados às tecnologias de poder presentes na tomada de decisão de determinados atores sociais.

Sobre o ensino técnico, nota-se com frequência que certas discussões filosóficas restringem-se ao questionamento da técnica em sua dimensão prática, como: avaliações qualitativas sobre o avanço e a utilidade da técnica, sobre as consequências da concepção tecnicista acerca da objetividade do mundo e do homem, ou ainda, como aponta Foucault (2010) sobre o desenvolvimento da racionalidade em que a técnica é analisada sob o viés progressista. Contudo, cabe à filosofia questionar a técnica pelo modo como a subjetividade se constitui na experiência com a técnica. Neste sentido, a partir 
das leituras de Heidegger e Foucault, a tarefa da filosofia é questionar a técnica fazendo um diagnóstico do presente (sentido ontológico), em que esse questionamento possibilite romper com a objetividade dominante da técnica e promova uma experiência ético-estética da mesma.

Com o resgate foucaultiano do conceito grego da téhcne ligado à vida (téchne tôu biou) buscou-se pensar o ensino da filosofia como um espaço da experiência de si. Para além de uma tradição que privilegiou o conhecimento de si, o que teve como resultado a elaboração de um saber sobre si e um ensino que se realiza como produção de verdade e transmissão de conteúdo. Sob outra perspectiva, precisamos pensar o modo como conduzimos nossa vida (bios), a uma maneira de ser e de fazer que possa criar o belo (arte da vida), em que o ensino possa ser pensado como uma maneira de cuidar que se realiza pela experiência de si.

Este é o lugar do ensino de filosofia, um espaço de experiência em que questionemos a técnica (como convida Heidegger) e cuidemos de nós mesmos (como aponta Foucault). Enfim, defendemos que o papel da filosofia no ensino técnico é o de construir um conceito de filosofia que possibilita compreender seu ensino como uma experiência singular do cuidado de si.

\section{Referências}

BRASIL. Ministério da Educação. Um novo modelo em educação profissional e tecnológica: concepção e diretrizes. Brasília, DF: MEC, 2010.

CASTRO, Edgardo. Vocabulário de Foucault: um percurso pelos seus temas, conceitos e autores. Tradução de Ingrid M. Xavier. Belo Horizonte: Autêntica, 2009.

CRAIA, Eladio Constantino Pablo. Gilles Deleuze e a questão da técnica, 2003. Tese (Doutorado) - Universidade Estadual de Campinas, Campinas, 2003.

DELEUZE, Gilles. Conversações, 1972-1990. Tradução de Peter Pál Pelbart. São Paulo: 34, 1992.

DUARTE, André de Macedo. Heidegger e a técnica. 2009. Disponível em: <http://works.bepress.com/cgi/viewcontent. cgi?article=1013\&context=andre_duarte $>$. Acesso em: 18 nov. 2014.

FOUCAULT, Michel. A coragem da verdade: o governo de si e dos outros II. Tradução de Eduardo Brandão. São Paulo: WMF Martins Fontes, 2011.

FOUCAULT, Michel. A hermenêutica do sujeito. Tradução de Márcio A. da Fonseca e Salma T. Muchail. São Paulo: Martins Fontes, 2004.

FOUCAULT, Michel. Arqueologia das ciências e história dos sistemas de pensamento. Tradução de Elisa Monteiro. 2. ed. Rio de Janeiro: Forense Universitária, 2005a.

FOUCAULT, Michel. Dits et ecrits IV: (1980-1988). Paris: Gallimard, 1994. Disponível em: <http://pt.scribd.com/doc/187478738/ Foucault-Michel-Dits-Et-Ecrits-Tome-4-1980-1988>. Acesso em: 04 fev. 2014.

FOUCAULT, Michel. Ética, sexualidade, política. Tradução de Elisa Monteiro e Inês A. D. Barbosa. 3. ed. Rio de Janeiro: Forense Universitária, 2012.

FOUCAULT, Michel. Microfísica do poder. Tradução de Roberto Machado. 21. ed. Rio de Janeiro: Graal, 2005b.

FOUCAULT, Michel. Nascimento da biopolítica: curso dado no Collège de France (1978-1979). Tradução de Eduardo Brandão. São Paulo: Martins Fontes, 2008.

FOUCAULT, Michel. 0 governo de si e dos outros: curso no Collège de France (1982-1983). Tradução de Eduardo Brandão. São Paulo: WMF Martins Fontes, 2010.

FOUCAULT, Michel. 0 que é a crítica? [Crítica e Aufklärung]. Disponível em: <http://vsites.unb.br/fe/tef/filoesco/foucault/biblio. html>. Acesso em: 12 maio 2010. 
FOUCAULT, Michel. Resumo dos cursos do Collège de France (1970-1982). Rio de Janeiro: Jorge Zahar, 1997.

FOUCAULT, Michel. Sobre a genealogia da ética: uma revisão do trabalho. In: RABINOW, Paul; DREYFUS, Hubert. Michel Foucault, uma trajetória filosófica: para além do estruturalismo e da hermenêutica. Tradução de Vera P. Carreto. Rio de Janeiro: Forense Universitária, 1995. p. 253-278.

FOUCAULT, Michel. Verdade e subjectividade (Howison Lectures). Revista de Comunicação e Linguagem, Lisboa. N. 19, p. 203223, 1993. Disponível em: <http://www.geledes.org.br/component/rsfiles/view?path=Michel_Foucault_obras_para_download/ foucault-m-verdade-e-subjetividade.pdf\&ltemid=622>. Acesso em: 10 mar. 2014.

FREITAS, Alexandre Simão. A parresía pedagógica de Foucault e o êthos da educação como psicagogia. Revista Brasileira de Educação, Rio de Janeiro, v. 18, n. 53, p. 325-493, abr./jun. 2013. Disponível em: <http://www.scielo.br/scielo.php?script=sci_ arttext\&pid=S1413-24782013000200005\&lang=pt>. Acesso em: 13 mar. 2014.

GALLO, Sílvio; ASPIS, Renata Lima. Ensino de filosofia e cidadania nas "sociedades de controle": resistência e linhas de fuga. ProPosições, Campinas, v. 21, n. 1, p. 89-105, jan./abr. 2010.

GELAMO, Rodrigo Pelloso. A questão da experiência no ensino da filosofia: um problema contemporâneo. Educação em Revista, Belo Horizonte, v. 26. n. 2, p. 383-400, ago. 2010.

GELAMO, Rodrigo Pelloso. 0 ensino da filosofia no limiar da contemporaneidade: 0 que faz o filósofo quando seu ofício é ser professor de filosofia? São Paulo: Cultura Acadêmica, 2009.

GROS, Frédéric. (Editor). In: FOUCAULT, Michel. A hermenêutica do sujeito. Tradução de Márcio A. da Fonseca e Salma T. Muchail. São Paulo: Martins Fontes, 2004. p. 591-595.

GROS, Frédéric. Situação do curso. In: FOUCAULT, Michel. A hermenêutica do sujeito. Tradução de Márcio A. da Fonseca e Salma T. Muchail. São Paulo: Martins Fontes, 2004. p. 613- 661.

GROS, Frédéric. Situação do curso. In: FOUCAULT, Michel. 0 governo de si e dos outros: curso no Collège de France (19821983). Tradução de Eduardo Brandão. São Paulo: WMF Martins Fontes, 2010. p. 341-356.

HEIDEGGER, Martin. A questão da técnica. Scientiæ Studia, São Paulo, v. 5, n. 3, 2007, p. 375-98.

HEIDEGGER, Martin. A época das imagens do mundo. Tradução de Claudia Drucker. Disponivel em: <http://ateus.net/artigos/ filosofia/a-epoca-das-imagens-de-mundo/pdf/>. Acesso em: 16 out. 2014.

PAGNI, Pedro Angelo. 0 cuidado de si em Foucault e suas possibilidades na educação: algumas considerações. In: SOUZA, Luís Antonio Francisco de; SABATINE, Thiago Teixeira; MAGALHÃES, Bóris Ribeiro de. (Org.). Michel Foucault: sexualidade, corpo e direito. Marilia: Oficina Universitária; São Paulo: Cultura Acadêmica, 2011. p. 19-45.

RABINOW, Paul; DREYFUS, Hubert. Michel Foucault, uma trajetória filosófica: para além do estruturalismo e da hermenêutica. Tradução de Vera P. Carreto. Rio de janeiro: Forense Universitária, 1995.

Recebido em: 13.01.2016

Aprovado em: 17.05.2016

Daniel Salésio Vandresen é doutorando em educação pela Universidade Estadual Paulista (Unesp) de Marília e mestre em filosofia pela Universidade Estadual do Oeste do Paraná (Unioeste) de Toledo. É professor do Instituto Federal do Paraná, Campus Coronel Vivida. É pesquisador do Grupo de Pesquisa: Filosofia, Ciência e Tecnologias.

Rodrigo Pelloso Gelamo é doutor em educação e mestre em filosofia pela Universidade Estadual Paulista (Unesp) de Marília. É professor do Programa de Pós-Graduação em Educação da Universidade Estadual Paulista (Unesp) de Marília. É pesquisador do Grupo de Estudos e Pesquisa em Educação e Filosofia (Gepef). 